\title{
Correlation of TTG IgA level with small intestinal histopathological changes for celiac disease among adult Saudi patients
}

\author{
Ibrahim S. Alharbi' ${ }^{1}$, Abdul Monem Sweid ${ }^{1}$, Muhammad Yousuf Memon ${ }^{2}$, Saeed \\ Alshieban $^{1}$, Ameirah Alanazi ${ }^{1}$ \\ ${ }^{1}$ King Abdul Aziz Medical city-National Guard Health Affairs (NGHA), King Abdullah Internaltinal Medical \\ Research Center (KAIMAC), King Saud Bin Abdul Aziz University for Health Sciences (KSAU-HS), Saudi Arabia; \\ 'Deprtment of Gastroenterology, King Abdul Aziz Medical city-National Guard Health Affairs (NGHA), King \\ Abdullah Internaltinal Medical Research Center (KAIMAC), King Saud Bin Abdul Aziz University for Health \\ Sciences (KSAU-HS), Saudi Arabia
}

\section{ABSTRACT}

Background and objectives: According to recent guidelines, a diagnosis of celiac disease (CD) can be made without a biopsy, especially in children. There are no enough studies despite high prevalence and differences in genetic, race, and cultures. Therefore, we examined the correlation between tissue transglutaminase (TTG) and duodenal biopsy changes in our region because we are identical and different from others in culture, environment, and habits, and the correlation is same as that in different regions. Methods: A retrospective cohort study at the Ministry of National Guard Health Affaires (NGHA) health care facilities that are distributed throughout kingdom of Saudi Arabia from April 19, 2015, till March 29, 2018. This study used the BESTCARE system that includes data from all NGHA facilities; data from 513 patients with CD were collected. All patients diagnosed with celiac disease aged 15 years or more, confirmed by improvement on gluten-free diet (GFD), and were not on GFD before endoscopy or serology test or both of them were included in the study, and the TTG IgA level was measured at the same time or within 2-3 months of biopsy date. The exclusion criteria were negative duodenal biopsy, which is less than 2; patients with negative biopsy and negative serology; patients who were on GFD before testing, and any patients known to have immunity diseases or illness causing mucosal changes. The TTG IgA level was measured in IU/ $\mathrm{mL}$ and was labeled as negative $(<20 \mathrm{IU} / \mathrm{mL})$ and positive $(\geq 20 \mathrm{IU} / \mathrm{mL})$ based on the cutoff value. However, Intestinal biopsy findings were identified as Marsh classification groups. Results: One hundred thirty-four patients who met the inclusion criteria were included in the study. Median age of our sample was 24 years (16-37 years). Among these, 99 (73.88\%) were female patients, whereas male patients were only $35(26.12 \%)$. Histopathologic investigation of intestinal biopsy were Marsh 0 group was 16 cases (11.9\%), Marsh 1 group was 8 cases (6\%), Marsh 2 group was 4 cases (3\%), Marsh 3a group was 32 cases (23.9\%), Marsh 3b group was 64 cases (47.8\%), and Marsh $3 c$ group was 10 cases (7.5\%). The TTG IgA antibody serology groups were $<20 \mathrm{IU} / \mathrm{mL}$ in 13 cases $(9.7 \%)$ and $\geq 20 \mathrm{IU} / \mathrm{mL}$ in 121 cases $(90.3 \%)$. Among all patients with CD who had negative biopsy (Marsh 0 group), 16 (100\%) of them had positive TTG IgA antibody. However, among patients with Marsh 1 group biopsy, $5(62.5 \%)$ cases had negative TTG IgA antibody compared with $3(37.5 \%)$ positive cases. Of the four cases (100\%) with Marsh 2 group, all of them had positive TTG IgA antibody. However, in Marsh 3a group biopsy, 3 (9.4\%) cases had negative TTG IgA antibody compared with $29(90.6 \%)$ cases with positive TTG IgA antibody. Furthermore, among the patients with Marsh $3 \mathrm{~b}$ group biopsy, $5(7.8 \%)$ had negative antibody and $59(92.2 \%)$ had positive serology. Of all biopsies of Marsh 3c group, 10 (100\%) had positive TTG IgA antibody. Conclusions: In perspective of high prevalence of CD in KSA, even more than western countries, we can pretend that positive TTG antibody tests can be applied for the diagnosis of CD without biopsy, particularly in symptomatic patients along with high titer, that is, 5-10 times the upper limit of normal (ULN). However, to validate it further, we need larger prospective studies in which duodenal biopsies should be taken according to recommended protocol and should be interpreted by experienced pathologist. Furthermore, biopsy is still needed in patients who do not show clinical improvement on a gluten-free diet and in cases with mildly or moderately elevated TTG IgA.

Key words: celiac disease, tissue transglutaminase IgA, Marsh classification 


\section{INTRODUCTION}

Celiac disease (CD) is chronic autoimmune disorder that affects genetically predisposed individuals who develop an immune reaction to gluten-containing food. The disease primarily affects the small intestine; however, the clinical manifestations are broad, with both intestinal and extraintestinal symptoms. ${ }^{[1]}$

Worldwide, the prevalence of the $\mathrm{CD}$ is approximately $1-2 \%$ and varies greatly from region to region. A recent large study conducted in Europe indicated the prevalence of $\mathrm{CD}$ as about $1 \%$, ranging from $0.3 \%$ in Germany to $2.4 \%$ in Finland. ${ }^{[2,3]}$ It appears to be greater in women than in men. CD is also common in extra-European countries, particularly the United States, South America, Middle East, Northern India, and North Africa, where the highest rate has been reported in the Sarahawi population. ${ }^{[4]}$

Several studies have shown that CD is increasing in many countries. It might be due to advanced diagnostic techniques and increased disease awareness. The rise in the prevalence has also been reported from historical $\mathrm{CD}$ areas (northern Europe and the United States), and more interestingly, it is spreading to new regions (Asian countries). The diet habits, particularly in gluten consumption and infant feeding patterns, are probably the main factors behind these new changes in CD epidemiology. ${ }^{[5]}$

The prevalence of CD in Middle Eastern and North African regions was lower than other regions. However, with the improvement in diagnostic techniques, $\mathrm{CD}$ has also been increasing in these regions ${ }^{[6]}$ and become similar to that of North American and European countries ${ }^{[7,8]}$

Two studies from Saudi Arabia suggested that it maight be one of the highest in the whole world. ${ }^{[9,10]}$

The prevalence observed in Saudi regions was as follows: Madinah, 1.8\%; Aseer, 2.1\%; and Al-Qaseem, $3.2 \%$. There was no statistically significant difference in the prevalence between Aseer and Al Qaseem. The prevalence in Madinah was significantly lower than that in other two regions.

$\mathrm{CD}$ is diagnosed by the combination of serologic testing and related duodenal histopathologic fidnings. However, according to recent guidelines, a diagnosis can be made without a biopsy, especially in children. ${ }^{[1]}$

Studies from different countries, including Europe, India, Iran, and Jordan, have demonstrated the linear relationship and strong correlation between the serologic tests and histopathologic changes. ${ }^{[12-13]}$

CD disease has been underestimated throughout the world; however, data are not sufficient to support it strongly and most of the studies were on children. Besides, there are differences in genetics, race, and culture, and many countries depend on studies performed by other countries.

\section{OBJECTIVES OF THE STUDY}

\section{Aim of the study}

It is important to find more evidence to support or oppose the notion for confirming the diagnosis of $\mathrm{CD}$ with serology and histopathology or serology alone.

\section{Specific objectives}

1. To study the correlation between tissue transglutaminase (TTG IgA) and duodenal biopsy changes in our patient population;

2. Compare our findings with other countries based on the differences in culture, environment, and habits.

\section{Secondary objectives}

To explore the prevalence of high T'TG IgA with negative biopsy in Cceliac disease

\section{METHODS}

This is a retrospective cohort study conducted at the Ministry of National Guard Health Affaires (NGHA), which includes King Abdulaziz Medical City in Riyadh City, King Abdulaziz Medical City in Jeddah City, Imam Abdulrahman Bin Faisal Hospital in Dammam City, King Abdulaziz Hospital in AlAhssa City, Prince Mohammad bin Abdulaziz Hospital in AlMadinah City, and primary healthcare centers that are distributed throughout the kingdom of Saudi Arabia from April 19, 2015, till March 29, 2018.

This study used the BESTCARE system, which includes data from all NGHA facilities; data from 513 patients with $\mathrm{CD}$ were collected.

The inclusion criteria were all adult patients diagnosed with $C D$, aged 15 years or above, improved on gluten-free diet (GFD) and had not been on GFD before endoscopy or serology test, and TTG IgA level was measured at the same time or within 2-3 months of biopsy date.

The exclusion criteria were

1. Negative duodenal biopsy less than 2 fragments;

2. Patients with negative biopsy and negative serology; 
3.Patients who were on GFD before testing;

4. Any patients known to have autoimmune disease or immunoglobulin deficiency that can cause similar histopathologic changes on small intestinal biopsy or false-negative serology.

$\mathrm{CD}$ is diagnosed by the combination of serologic testing (TTG IgA antibody titers) and small bowel histopathology findings. The TTG IgA level was measured in $\mathrm{IU} / \mathrm{mL}$ and was labeled as negative $(<20 \mathrm{IU} / \mathrm{mL})$ and positive $(\geq 20 \mathrm{IU} /$ $\mathrm{mL}$ ) based on the cutoff value, whereas duodenal biopsy findings were identified as Marsh classification groups:

Marsh 0: normal: <30 IEL, normal crypts, normal villi;

Marsh 1: > 30 IEL, normal crypts, normal villi;

Marsh 2: > 30 IEL, crypt hyperplasia, normal villi;

Marsh 3a: > 30 IEL, crypt hyperplasia, mild villous atrophy; Marsh 3b: > 30 IEL, crypt hyperplasia, marked villous atrophy; Marsh 3c: >30 IEL, crypt hyperplasia, complete villous atrophy.

\section{Statistical analysis}

Data were analyzed using the statistical software; IBM SPSS Statistics 22.0 (SPSS, Inc., Chicago, IL). Demographic and descriptive data for categorical variables were expressed as count and percentage. For continuous variables, data were reported as median and interquartile range. The association between TTG IgA antibody titers and intestinal biopsy groups was assessed using Chi-square test. A Spearman's rho correlation test was used between TTG IgA antibody titers and intestinal biopsy groups. The normality of the data was assessed using a Shapiro-Wilk test. A 2-tailed $P$-value of $\leq 0.05$ will be considered statistically significant.

\section{RESULTS}

One hundred thirty-four patients who met the inclusion criteria were included in the study. Median age of our sample was 24 years (16-37 years). Among these, 99 $(73.88 \%)$ were female patients, whereas only $35(26.12 \%)$ were male patients. Histopathologic findings of intestinal biopsy were divided based on the Marsh classification in consultation with histopathologist: Majority of patients were in Marsh 3a and 3b, that is, $32(23.9 \%)$ and 64 cases (47.8\%), respectively. Marsh 0 group was also notable with 16 cases $(11.9 \%)$, whereas Marsh 1, 2, and 3c groups comprised only 8 cases $(6 \%), 4$ cases $(3 \%)$, and 10 cases $(7.5 \%)$, respectively.

The TTG IgA antibody serology group with $\geq 20$ IU/ $\mathrm{mL}$ constituted the major part of the patients, that is, 121 $(90.3 \%)$ versus $13(9.7 \%)$ with $<20 \mathrm{IU} / \mathrm{mL}$ (Table 1$)$.

Among all patients with CD who had negative biopsy (Marsh 0 group), all $16(100 \%)$ patients had positive TTG IgA antibody. However, among patients with Marsh 1 group, 5 of 8 (62.5\%) cases had negative TTG IgA antibody. Marsh 2 group comprised only 4 cases and all of them had positive TTG IgA antibody, whereas in Marsh 3a group, 3 of $32(9.4 \%)$ cases had negative TTG IgA antibody compared with 29 (90.6\%) with positive TTG IgA antibody. Furthermore, among patients with Marsh 3b group, 5 of $64(7.8 \%)$ had negative antibody and $59(92.2 \%)$ had positive serology. Of all biopsies of Marsh 3c group, all $10(100 \%)$ had positive TTG IgA antibody (Table 2). For detailed biopsy group distribution within TTG IgA antibody cases, refer to Table 2, 3, and Figure 1.

The prevalence of cases with high TTG IgA antibody $(n=121)$ and negative intestinal biopsy $(n=16)$ was $13.22 \%$ (Table 2). A Spearman correlation was performed to assess the relationship between biopsy groups and TTG IgA antibody titers. There was a moderate positive correlation between intestinal biopsy groups and TTG IgA antibody titers $(r=0.4)$, which is statistically significant at $P$-value of 0.001 (Table 4).

\section{Table 1: Baseline Characteristics of Celiac patients.}

Characteristics

Age (Median, IQR)

Sex, $n(\%)$

Marsh Intestinal biopsy groups, $n(\%)$

TTG IgA groups, $n$ (\%)
Total $(n=134)$

$24(16-37)$

$35(26.1)$

99 (73.9)

$16(11.9)$

$8(6)$

4 (3)

$32(23.9)$

$64(47.8)$

$10(7.5)$

$13(9.7)$

$121(90.3)$ 
Table 2: General distribution of Intestinal biopsy groups with TTG IgA groups.

\begin{tabular}{|c|c|c|c|c|}
\hline & & \multicolumn{2}{|c|}{ TTG IgA Antibody titres } & \multirow{2}{*}{$\begin{array}{c}\text { Total } \\
(n=134)\end{array}$} \\
\hline & & $\begin{array}{c}\text { Negative } \\
(<20 \mathrm{IU} / \mathrm{mL}) \\
(n=13,9.7 \%)\end{array}$ & $\begin{array}{c}\text { Positive } \\
(\geq 20 \mathrm{lU} / \mathrm{mL}) \\
(n=121,90.3 \%)\end{array}$ & \\
\hline \multirow{6}{*}{$\begin{array}{l}\text { Marsh Intestinal biopsy groups } \\
\text { ( } n \text { [\%] within groups) }\end{array}$} & 0 & $0(0)$ & $16(100)$ & 16 \\
\hline & 1 & $5(62.5)$ & $3(37.5)$ & 8 \\
\hline & 2 & $O(0)$ & 4 (100) & 4 \\
\hline & $3 a$ & $3(9.4)$ & $29(90.6)$ & 32 \\
\hline & $3 b$ & $5(7.8)$ & $59(92.2)$ & 64 \\
\hline & $3 c$ & $O(0)$ & $10(100)$ & 10 \\
\hline
\end{tabular}

\begin{tabular}{|c|c|c|c|c|}
\hline & & \multicolumn{3}{|c|}{ TTG IgA 3 groups } \\
\hline & & $<20$ & $20-100$ & $>100$ \\
\hline & & $(n=13,10 \%)$ & $(n=27,20 \%)$ & $(n=94,70 \%)$ \\
\hline \multirow{6}{*}{$\begin{array}{l}\text { Marsh Intestinal } \\
\text { biopsy groups }\end{array}$} & 0 & $0(0.0 \%)$ & $10(37.0 \%)$ & $6(6.4 \%)$ \\
\hline & 1 & $5(38.5 \%)$ & $2(7.4 \%)$ & $1(1.1 \%)$ \\
\hline & 2 & $0(0.0 \%)$ & $0(0.0 \%)$ & $4(4.3 \%)$ \\
\hline & $3 a$ & $3(23.1 \%)$ & $5(18.5 \%)$ & $24(25.5 \%)$ \\
\hline & $3 b$ & $5(38.5 \%)$ & $8(29.6 \%)$ & $51(54.3 \%)$ \\
\hline & $3 c$ & $0(0.0 \%)$ & $2(7.4 \%)$ & $8(8.5 \%)$ \\
\hline
\end{tabular}

Table 4: Correlation between intestinal biopsy groups and TTG IgA antibody titers.

\begin{tabular}{lll}
\hline & Marsh Intestinal biopsy groups & $P$-value \\
\hline Spearman's RHO TTG IgA & $0.369^{*}$ & $0.001^{*}$ \\
\hline
\end{tabular}

* Correlation is significant at the 0.05 level (2-tailed).

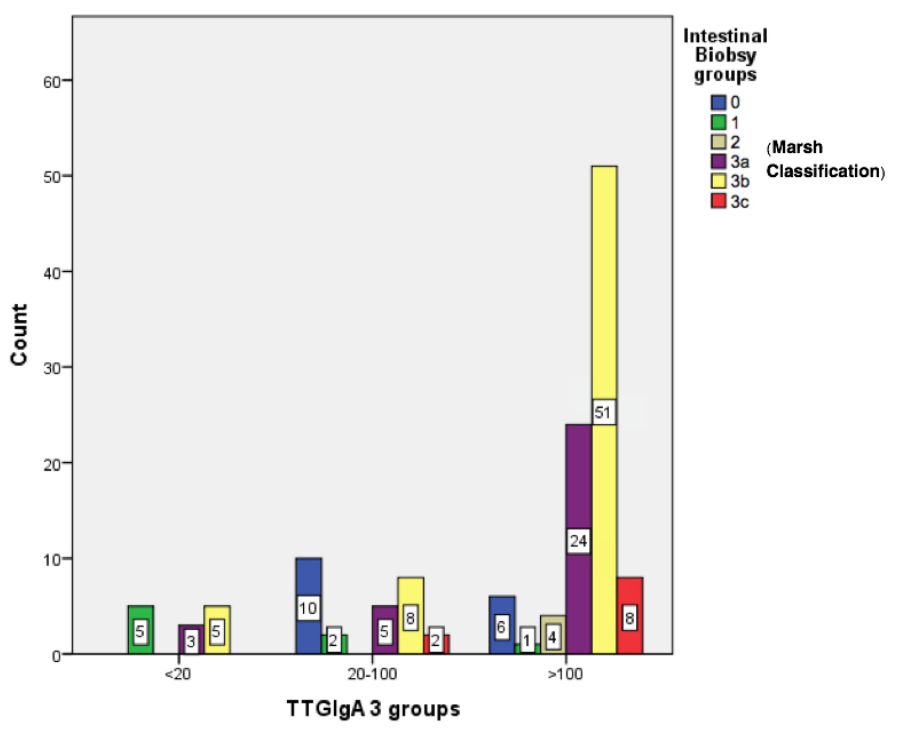

Figure 1: Distribution of Intestinal biopsy groups and TTG IgA antibody titers. 
Alharbi et al.: Correlation of TTG IgA level with small intestinal biopsy for celiac disease

\section{DISCUSSIONS}

Diagnosis of CD traditionally depends on the combination of serologic markers and intestinal biopsies. The European and North American gastroenterology society guidelines require a biopsy for diagnosis; however, in some recent guidelines, there have been some relaxation for the biopsy part and it is diagnosed solely by serology. ${ }^{[14,15]}$ Recent guidelines have proposed that there is a correlation between TTG antibody titers and degree of small bowel changes on duodenal biopsy and that duodenal biopsy can be omitted in some patients with high levels of TTG antibody. ${ }^{[16]}$ In this perspective, according to Donaldson et al., antibody testing showed high accuracy, particularly in symptomatic patients, and TTG IgA is considered to be one of the firstline tests in recently updated clinical guidelines. ${ }^{[17]}$

We conducted this study to determine the correlation between TTG IgA and duodenal biopsy changes in our region and compare with other data. Age distribution in our study starts from 16 years because we did not include patients below 15 years of age. However, the maximum age in our study was 37 years with the range of 16-37 years. This is in contradiction with one study conducted in Denmark particularly for demographic purpose, ${ }^{[18]}$ in which they found age range from 0 to 88 years. Female preponderance in our study $(73 \%)$ is comparable with this as well as other international studies. ${ }^{[19]}$ Extensive literature review and meta-analysis performed by McCarty et al. ${ }^{[20]}$ revealed that duodenal bulb biopsy increases the diagnostic yield by $5 \%$ and $4 \%$ in adults and children, respectively. In our study, although there was no strict criteria for duodenal bulb biopsy, but overall $9.3 \%(n=13)$ of patients with CD were diagnosed on biopsy alone, with TTG IgA level $<20$ units. Conversely, $13.22 \%(n=16)$ patients had positive serology but negative biopsy but was labeled as celiac based on the response to GFD. False-positive TTG IgA antibodies are very rare, ${ }^{[21]}$ are typically of low titer, and more often occurs with older assays. It could also be attributed to potential $\mathrm{CD}$, where patients develop clinical features and histologic findings late, although TTG IgA will be positive quite early in the course. ${ }^{[22]}$ In our study positive predictive value of TTG IgA in relation to biopsy result was $88.6 \%$, which means that in this study, 118 of 134 patients had positive biopsy. This is comparable with one study coducted in the Netherlands where PPV was $89 \%$. However, considering all patients had CD, based on the response to GFD irrespective of biopsy results, PPV may be assumed as 100\% in our study. Biopsy yield may be increased further by following the recommended protocol for duodenal biopsy, that is, 4 from distal duodenum and 2 from bulb. ${ }^{[23]}$ Furthermore, experienced histopathologist in relevant field might matter in improving diagnostic yield. ${ }^{[24]}$
Various studies propose that high levels of circulating immunoglobulin IgA tissue transglutaminase (TTG2) antibodies can predict $C D$ with high specificity. The optimal cutoff point of IgA anti-TTG level to recognize patients who may not need a biopsy varies between assays. Some reports suggest a cutoff point of a TTG IgA titer $>10$ times the upper limit of normal (ULN), ${ }^{[25]}$ whereas others such as Zanini et al. ${ }^{[26]}$ found that titers exceeding 5 times the ULN showed 100\% specificity and PPV for duodenal atrophy. Alessio $e t$ al. ${ }^{[27]}$ reported that all patients with IgA anti TTG IgA titers $>7$ times the ULN showed histologic features of $\mathrm{CD}$.

Others found that when the TTG IgA titer is $>100 \mathrm{U} /$ $\mathrm{mL}$, biopsy is not mandatory to confirm the diagnosis, particularly in symptomatic patients. ${ }^{[28]}$

However, it is quite common to observe histologic findings of Marsh 3 in patient having TTG antibody levels $>100$ units and for Beltran et al., it was possible to characterize a TTG2 antibody cutoff with $100 \%$ specificity for Marsh 3 histology, at just $>10$ times the ULN. ${ }^{[29]}$ In our study, $70 \%(n=94)$ of patients had TTG IgA levels $>100$ units. Of this, $92.5 \%(n=87)$ of patients belongs to Marsh intestinal biopsy 2 and above. It is also notable that 13 patients had $<20$ units of TTG IgA antibody levels, and of this, 8 patients were also found to be have histological changes of Marsh group 2 and above for intestinal biopsy group. It is also evident that lack of technical proficiency with grasping biopsy forceps and failure to follow protocol of endoscopic duodenal biopsy make the possibility of CD diagnosis in only $90 \%$ of cases. ${ }^{[30]}$ Furthermore, $\mathrm{CD}$ may be missed during histologic examinations owing to variations in different pathologist's assessments. ${ }^{[1]}$

\section{CONCLUSION}

In the perspective of high prevalence of CD in KSA, even more than western countries, we can pretend that positive TTG IgA antibody tests can be applied for the diagnosis of $C D$ without biopsy, particularly in symptomatic patients along with high titer, that is, 5-10 times the ULN. However, to validate it further, we need large-scale prospective studies in which duodenal biopsies should be taken according to the recommended protocol and should be interpreted by experienced pathologist. Furthermore, biopsy is still needed in patients who do not show clinical improvement on a GFD and in cases with mildly or moderately elevated TTG IgA.

\section{Conflict of Interest}

None declared. 


\section{REFERENCES}

1. Lebwohl B, Sanders DS, Green PHR. Coeliac disease. Lancet 2018;391:7081.

2 Lohi S, Mustalahti K, Kaukinen K, Laurila K, Collin P, Rissanen H, et al. Increasing prevalence of coeliac disease over time. Aliment Pharm Ther 2007; 26: $1217-25$.

3. Mustalahti K, Catassi C, Reunanen A, Fabiani E, Heier M, McMillan S, et al. The prevalence of celiac disease in Europe: results of a centralized, international mass screening project. Ann Med 2010; 42:587-95.

4. Catassi C, Rätsch IM, Gandolfi L, Pratesi R, Fabiani E, El Asmar R, et al. Why is celiac disease endemic in the people of Sahara? Lancet 1999; 354: 647-8.

5. Catassi C, Gatti S, Fasano A. The new epidemiology of celiac disease. J Pediatr Gastroenterol Nutr 2014; 59:S7-9.

6. Rostami K, Malekzadeh R, Shahbazkhani B, Akbari MR, Catassi C. Coeliac disease in Middle Eastern countries: a challenge for the evolutionary history of this complex disorder? Dig Liver Dis 2004;36:694-7.

7. Akbari MR, Mohammadkhani A, Fakheri H, Javad Zahedi M, Shahbazkhani B, Nouraie M, et al. Screening of the adult population in Iran for coeliac disease: comparison of the tissue-transglutaminase antibody and anti-endomysial antibody tests. Eur J Gastroenterol Hepatol 2006;18:1181-6.

8. Ben Hariz M, Kallel-Sellami M, Kallel L, Lahmer A, Halioui S, Bouraoui $\mathrm{S}$, et al. Prevalence of celiac disease in Tunisia: mass-screening study in schoolchildren. Eur J Gastroenterol Hepatol 2007;19:687-94

9. Khayyat YM. Serologic markers of gluten sensitivity in a healthy population from the western region of Saudi Arabia. Saudi J Gastroenterol 2012;18:23-5.

10. Aljebreen AM, Almadi MA, Alhammad A, Al Faleh FZ. Seroprevalence of celiac disease among healthy adolescents in Saudi Arabia. World J Gastroenterol 2013;19:2374-8.

11. Kelly CP, Bai JC, Liu E, Leffler DA. Advances in diagnosis and management of celiac disease. Gastroenterology 2015;148:1175-86.

12. Raimondi G, Mezzina I, Tripaldi ME, Castellaneta S, Cristofori F, Ciullo $\mathrm{C}$, et al. Tissue transglutaminase antibody cut-off and diagnosis of celiac disease. Dig Liver Dis 2015; 47:e272.

13. Shomaf M, Rashid M, Faydi D, Halawa A. Is the Diagnosis of Celiac Disease Possible Without Intestinal Biopsy? Balkan Med J 2017;34:313-7.

14. Husby S, Koletzko S, Korponay-Szabó IR, Mearin ML, Phillips A, Shamir $\mathrm{R}$, et al. European Society for Pediatric Gastroenterology, Hepatology, and Nutrition guidelines for the diagnosis of coeliac disease. J Pediatr Gastroenterol Nutr 2012; 54:136-60.

15. Vivas S, Ruiz de Morales JG, Riestra S, Arias L, Fuentes D, Alvarez N, et al. Duodenal biopsy may be avoided when high transglutaminase antibody titers are present. World J Gastroenterol 2009;15:4775-80.

16. Rahmati A, Shakeri R, Sohrabi M, Alipour A, Boghratian A, Setareh M, et al. Correlation of tissue transglutaminase antibody with duodenal histologic marsh grading. Middle East J Dig Dis 2014;6:131-6.

17. Walker MM, Murray JA, Ronkainen J, Aro P, Storskrubb T, D’Amato M, et al. Detection of celiac disease and lymphocytic enteropathy by parallel serology and histopathology in a population-based study. Gastroenterol- ogy 2010;139:112-9.

18. van Gils T, Rootsaert B, Bouma G, Mulder CJ. Celiac Disease in the Netherlands: Demographic Data of Members of the Dutch Celiac Society. J Gastrointestin Liver Dis 2016; 25: 441-5.

19. Mubarak A, Wolters VM, Gmelig-Meyling FH, Ten Kate FJ, Houwen RH. Tissue transglutaminase levels above $100 \mathrm{U} / \mathrm{mL}$ and celiac disease: A prospective study. World J Gastroenterol 2012;18: 4399-403.

20. McCarty TR, O'Brien CR, Gremida A, Ling C, Rustagi T. Efficacy of duodenal bulb biopsy for diagnosis of celiac disease: a systematic review and meta-analysis. Endosc Int Open 2018;6: 1369-78.

21. Swallow K, Wild G, Sargur R, Sanders DS, Aziz I, Hopper AD, et al. Quality not quantity for transglutaminase antibody 2: the performance of an endomysial and tissue transglutaminase test in screening coeliac disease remains stable over time. Clin Exp Immunol 2013; 171:100-6.

22. Ludvigsson JF, Leffler DA, Bai JC, Biagi F, Fasano A, Green PH, et al. The Oslo definitions for coeliac disease and related terms. Gut 2013;62:43-52.

23. Iacucci M, Ghosh S. Routine duodenal biopsies to diagnose celiac disease. Can J Gastroenterol 2013;27:385.

24. Mubarak A, Nikkels P, Houwen R, Ten Kate F. Reproducibility of the histological diagnosis of celiac disease. Scand J Gastroenterology 2011; 46:1065-73.

25. Hill ID. What are the sensitivity and specificity of serologic tests for celiac disease? Do sensitivity and specificity vary in different populations? Gastroenterology 2005;128:S25-32.

26. Zanini B, Magni A, Caselani F, Lanzarotto F, Carabellese N, Villanacci V, et al. High tissue-transglutaminase antibody level predicts small intestinal villous atrophy in adult patients at high risk of celiac disease. Dig Liver Dis 2012;44:280-5.

27. Alessio MG, Tonutti E, Brusca I, Radice A, Licini L, Sonzogni A, et al. Correlation between IgA tissue transglutaminase antibody ratio and histological finding in celiac disease. J Pediatr Gastroenterol Nutr 2012;55:44-9.

28. Rostom A, Dube C, Cranney A, Saloojee N, Sy R, Garritty C, et al. The diagnostic accuracy of serologic tests for celiac disease: a systematic review. Gastroenterology 2005;128:S38-46.

29. Beltran L, Koenig M, Egner W, Howard M, Butt A, Austin MR, et al. High-titre circulating tissue transglutaminase-2 antibodies predict small bowel villous atrophy, but decision cut-off limits must be locally validated. Clin Exp Immunol 2014; 176:190-8.

30. Collin P, Kaukinen K, Vogelsang H, Korponay-Szabó I, Sommer R, Schreier E, et al. Antiendomysial and antihuman recombinant tissue transglutaminase antibodies in diagnosis of coeliac disease: a biopsy-proven European multicentre study. Eur J Gastroenterol Hepatol 2005;17:85-91.

31. Mubarak A, Nikkels P, Houwen R, Ten Kate F. Reproducibility of the histological diagnosis of celiac disease. Scand J Gastroenterology 2011, 46:1065-73.

How to cite this article: Alharbi IS, Sweid AM, Memon MY, Alshieban S, Alanazi A. Correlation of TTG IgA level with small intestinal histopathological changes for celiac disease among adult Saudi patients. J TransI Int Med 2020; 8: 48-53. 